\title{
Anti-angiogenic Therapy in Cancer: Downsides and New Pivots for Precision Medicine
}

\begin{abstract}
Gabriella Lupo, Nunzia Caporarello, Melania Olivieri, Martina Cristaldi, Carla Motta, Vincenzo Bramanti, Roberto Avola, Mario Salmeri, Ferdinando Nicoletti and Carmelina D. Anfuso*
\end{abstract}

Department of Biomedical and Biotechnological Sciences, School of Medicine, University of Catania, Catania, Italy

Primary solid tumors originate close to pre-existing tissue vasculature, initially growing along such tissue blood vessels, and this phenomenon is important for the metastatic potential which frequently occurs in highly vascularized tissues. Unfortunately, preclinic and clinic anti-angiogenic approaches have not been very successful, and multiple factors have been found to contribute to toxicity and tumor resistance. Moreover, tumors can highlight intrinsic or acquired resistances, or show adaptation to the VEGF-targeted therapies. Furthermore, different mechanisms of vascularization, activation of alternative signaling pathways, and increased tumor aggressiveness make this context even more complex. On the other hand, it has to be considered that the transitional restoration of normal, not fenestrated, microvessels allows the drug to reach the tumor and act with the maximum efficiency. However, these effects are time-limited and different, depending on the various types of cancer, and clearly define a specific "normalization window." So, new horizons in the therapeutic approaches consist on the treatment of the tumor with pro- (instead of anti-) angiogenic therapies, which could strengthen a network of well-structured blood vessels that facilitate the transport of the drug.

Keywords: tumor angiogenesis, anti-angiogenic therapy, tumor endothelial cells (TECs), pericytes, vascular normalization, microvascular architecture, hypoxia detection

\section{CANCER-RELATED ANGIOGENESIS AND ANTI-ANGIOGENIC THERAPY}

The blood vessels supplying tumors are permeable, tortuous, heterogeneous in their morphological structure and efficiency of perfusion, and greatly different from those composing the normal vasculature. These features determine what is now called "aberrant angiogenesis," which characterizes the tumor environment (Huang et al., 2013).

One of the obstacles to the success of cancer treatment is related to inefficient transport of drugs to cancer cells. Due to lack of proper interconnections between the endothelial cells (ECs), tumor blood vessels are fenestrated and this constitutes a major impediment to the transport and even distribution of the chemotherapy to the tumor tissue (Maes et al., 2016) (Figure 1A,a).

Another characteristic of tumor vessels is the lack of pericytes which makes the wall of the vessel thin, changing the permeability within the same tumor and between different tumors (Jain, 2013). The abnormal vascularity can make tumors resistant to chemotherapeutic agents. 
A

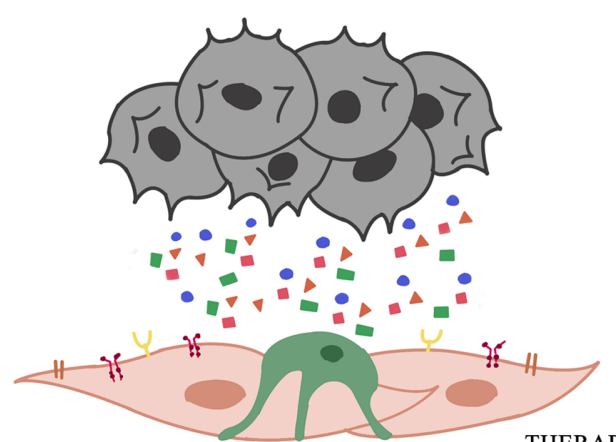

ANTI - ANGIOGENIC THERAPY
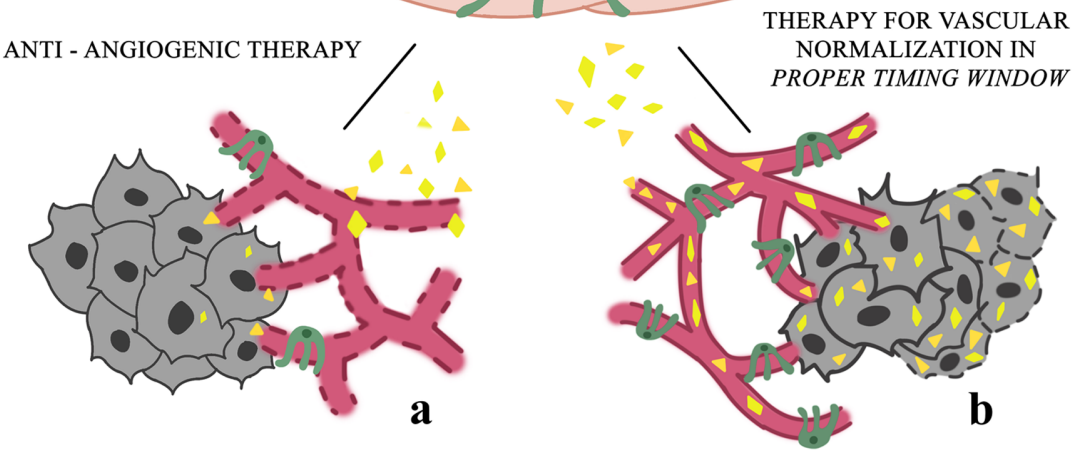

B

\section{PREDICTIVE DETECTION}

- MRI: MVD, VAI

- PET: Hypoxia (HIF)

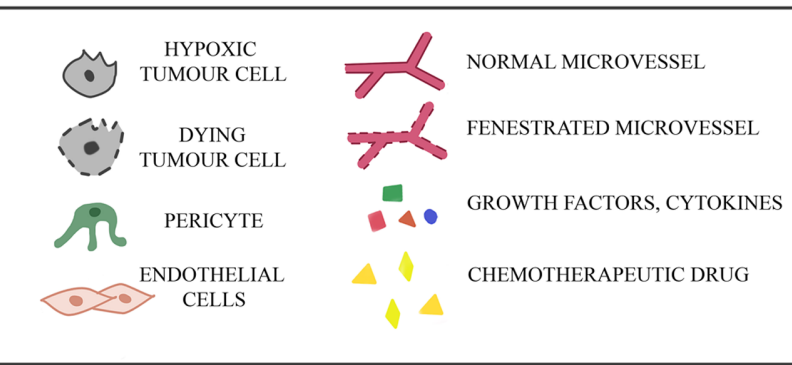

FIGURE 1 | Proposed mechanisms of microvessel responses to anti-angiogenic therapy. (A) Tumors may initially respond to anti-angiogenic therapy in different ways, and this response depends on the integrity of microcirculation. (a) Because of the presence of fenestrated vessels with a poor pericyte coverage, chemotherapeutic drug cannot reach the targeted tumor site. Consequently, tumor stabilizes or progresses. (b) The association of an anti-angiogenic drug with an anti-tumor drug in a proper timing window restores a balance between pro- and anti-angiogenic factors, leading to the normalization of blood vessels: the chemotherapeutic drug can reach the targeted tumor site. These effects are limited spatially and temporally, and are different in different types of cancers, particularly in the case of little vascularized tumors. (B) The predictive detection of microvessel architectural parameters is necessary for the selection of a precision and personal therapy, aimed to the vascular normalization, being these parameters based on Magnetic Resonance Imaging (MRI), Vessel Architectural Imaging (VAl), Microvascular Density (MVD), Positron Emission Tomography (PET). 
The treatment against many types of cancer based on the administration of chemotherapeutic drugs is supported by the use of molecules with anti-angiogenic activity, aimed at reducing tumor blood vessel increase in order to inhibit tumor growth (Teng et al., 2010) (Figure 1A).

Phase 3 clinical trials of VEGF pathway inhibitors have shown a significant heterogeneity of tumor response to treatment: tumors can respond to the anti-angiogenic therapy or can give a partial or even no response. A classification of sensitive, partially sensitive and insensitive tumors is reported in Table 1.

Moreover, tumor vascularisation may occur via alternative mechanisms, which include intussusceptive microvascular growth (Nico et al., 2010), glomeruloid angiogenesis (Straume et al., 2002), looping angiogenesis (Kilarski et al., 2009), vessel co-option and vasculogenic mimicry (Folberg and Maniotis, 2004).

Comparative studies have reported the existence of molecular differences, genetic alterations and drug resistance between normal ECs (NECs) and tumor ECs (TECs). Specific genes for TECs [named tumor endothelial markers (TEMs)] have been shown, and 13 novel cell-surface TEM proteins have been classified (Nanda and Croix, 2004) and are overexpressed during physiological angiogenesis (Seaman et al., 2007). For instance, a VEGF autocrine loop in the first confers resistance to serum starvation, differently from NECs, and TECs are more responsive to VEGF and bFGF than NECs (Matsuda et al., 2010). TECs from highly metastatic tumors show increased sensitivity to VEGF, have less pericyte coverage (Ohga et al., 2012) and disclose the upregulation of angiogenesis-related genes and pathways (Adya et al., 2008). Moreover, tumor cells are able to transdifferentiate into TECs (Wang et al., 2010). Therefore, antineoplastic agents, could not only fail to have access to the tumor mass, but are also relatively active because cells in hypoxia implement mechanisms of resistance (Ebos et al., 2009). All this may explain why a tumor, while being highly vascularised, is often resistant to chemotherapy.

\section{ANTI-ANGIOGENIC THERAPIES: THE OTHER SIDE OF THE COIN}

\section{Tumor Heterogeneity of Response to Anti-angiogenic Therapies}

Although the anti-VEGF treatments have constituted a milestone for anti-angiogenic purposes, another aspect of this framework has to be considered in that VEGF inhibitors often fail to produce enduring clinical responses in a great number of patients (Saltz et al., 2007). The anti-angiogenic therapy results in transitory improvements, in the form of tumor standstill or constriction, in some cases increasing survival. In spite of this, tumors begin to grow again, though after a transient period of clinical benefit, generally measured in months (Miller et al., 2005).

Regarding the resistance to the VEGF-targeted therapy, two mechanisms through which this endurance is highlighted can be defined: (i) tumors completely fail to respond from the outset of treatment (intrinsic resistance) or (ii) they respond initially, and then continue growing while still receiving the treatment (acquired resistance; Bergers and Hanahan, 2008).

\section{Microvascular Heterogeneity of Response to Anti-angiogenic Therapies}

A critical occurrence leading to the success or failure of antiangiogenic therapy is the need for a proper timing window for tumor vascular normalization: long term anti-angiogenic therapy sometimes leads to tumor hypoxia (Winkler et al., 2004), and hypoxia triggers VEGF production, genetic instability in tumor ECs and vascular permeability (Taylor et al., 2010). The decrease in blood flow further reduces oxygen, nutrient and drug delivery, enforcing stress on the tumor (Figure 1A,a). In preclinical studies, VEGF-targeted therapy suppresses the growth of new tumor vessels, but is less effective against the established tumor vessels (Sitohy et al., 2012). Nagy and Dvorak (2012) postulated that "early" and "late" tumor vessels might differ in the susceptibility to anti-VEGF therapies. "Early" vessels would predominate initially; the "late" ones become proportionately greater, however, as tumors grow. While the

TABLE 1 | Tumor response to anti-angiogenic therapy.

\begin{tabular}{|c|c|c|c|c|}
\hline \multicolumn{5}{|c|}{ Anti-angiogenic therapy } \\
\hline Tumor & Sensitive & Partially sensitive & Insensitive & Reference \\
\hline Breast cancer & & $\checkmark$ & & Fakhrejahani and Toi, 2014; Earl et al., 2015 \\
\hline Clear cell renal carcinoma & $\checkmark$ & & & Hutson et al., 2014; Rini et al., 2014 \\
\hline Colorectal cancer & & $\checkmark$ & $\checkmark$ & Bennouna et al., 2013; Grothey et al., 2013 \\
\hline Gastroesophageal cancer & & $\checkmark$ & & Fuchs et al., 2014; Wilke et al., 2014 \\
\hline Glioma & & $\checkmark$ & & Gilbert et al., 2014 \\
\hline Hepatocellular carcinoma & $\checkmark$ & & & Bruix et al., 2015; Cainap et al., 2015 \\
\hline Lung cancer & & $\checkmark$ & & Garon et al., 2014; Liang et al., 2014 \\
\hline Neuroendocrine and thyroid cancer & $\checkmark$ & & & Brose et al., 2014 \\
\hline Ovarian and cervical cancer & $\checkmark$ & & & Pujade-Lauraine et al., 2014; Tewari et al., 2014 \\
\hline Pancreatic cancer & & & $\checkmark$ & Kindler et al., 2010 \\
\hline Prostate cancer & & & $\checkmark$ & Michaelson et al., 2014 \\
\hline
\end{tabular}


former are responsive, the latter (though formed from the "early" vessels) lose their dependence to the growth factor and become resistant to anti-VEGF-A/VEGFR therapy. Furthermore, the enormous heterogeneity of the tumor vasculature has to be considered, and different types of evolving resistant surrogate tumor blood vessels, which vary between them in anti-VEGF therapy sensitivity, have been described (Sitohy et al., 2012). These aberrant new vessels may be VEGF-independent and therefore capable of mediating tumor vascularisation despite VEGF-inhibition. For example, brain tumors become more infiltrating after VEGF pathway inhibition, which may facilitate vessel co-option (Keunen et al., 2011).

\section{Cancer Adaptation}

Microenvironment adaptation to a cancer stress condition plays a key role in determining whether tumors respond to VEGFtargeted therapies (Rak et al., 2002). This event is driven in part by the molecular promotion of the translation of prosurvival genes, such as BCL2 (Sherrill et al., 2004), X-linked inhibitor of apoptosis protein (XIAP; Gu et al., 2009), and stress response genes (Somers et al., 2015). It has been shown that under the hypoxic condition, which inhibits the global protein synthesis, the eIF4E homolog $4 \mathrm{EHP}$ can promote the translation of certain mRNAs involved in the adaptation to hypoxia, such as EGF receptor and PDGF receptor- $\alpha$ (Uniacke et al., 2012). Preclinical data has shown that some adaptive mechanisms include a decreased propensity for certain cancer cells to die under stress conditions, sometimes following genetic aberrations such as loss of p53 function (Yu et al., 2002), by adapting their metabolism (McIntyre et al., 2012) or by autophagy (Xu et al., 2013). In addition to being constituted by transformed cells, tumors are characterized by the presence of infiltrating different stromal cells, which are often the cause of therapy resistance, including the resistance to anti-angiogenic therapies (McMillin et al., 2013). Among these, the immature myeloid cells (Chung et al., 2013), fibroblasts (Crawford et al., 2009) and endothelial progenitor cells (Shaked et al., 2006) infiltrate the tumor and mediate the resistance by incorporating themselves into vessels or by releasing pro-angiogenic growth factors, such as BV8 (Shojaei et al., 2007) or PDGF-C (Crawford et al., 2009). At present, there is conflicting evidence to whether the antiangiogenic therapy could increase the tumor aggressiveness and cause flare phenomena. In some pre-clinical studies the antiVEGF treatment promoted this serious downside, in terms of invasion and metastasis (Ebos et al., 2009). Also, evidence in patients showed that anti-VEGF therapy can promote tumor aggression. A study on metastatic renal cancer cell (mRCC) patient demonstrated a significant increase in tumor grade in the primary tumor after treatment with sunitinib and pazopanib (Sharpe et al., 2013), while data from the AVANT trial for colorectal cancer with adjuvant bevacizumab has highlighted that this treatment caused a higher incidence of relapses and deaths (de Gramont et al., 2012). Moreover, anti-VEGF therapy can promote invasion and the undergoing epithelial-to-mesenchymal transition (Lu et al., 2012). In our and other researchers' opinion, a possible mechanism could be that the anti-angiogenic treatment damages the vessels, causing cancer cell extravasation; in preclinical models, TKIs may promote metastasis by damaging the vasculature integrity (Chung et al., 2012). On the other hand, flare-up phenomena have been described in patients with mRCC after the withdrawal of the anti-angiogenic therapy (Powles et al., 2013), and the analysis of the NSABP-C08 trial of adjuvant bevacizumab in colorectal cancer patients did not evidence the noxious effect of bevacizumab (Allegra et al., 2013).

\section{Evidences of Toxicity}

Clinical practices have revealed a large number of adverse complications associated with anti-VEGF treatments. Among these, hypertension, proteinuria, hemorrhage, endocrine dysfunction, thrombosis, gastrointestinal perforation, fistula formation, cardiac toxicity, and reversible posterior leukoencephalopathy (Chen and Cleck, 2009). The need for hypertension treatment has been seen in approximately 25\% of patients (Burger et al., 2011). The occurrence of reversible posterior leukoencephalopathy is correlated with uncontrolled hypertension and the permanent cessation of VEGF inhibitor therapy is greatly needed. VEGF inhibitors could also increase the risk of thromboembolism by about $5 \%$, and anticoagulant treatments were active in reducing this side effect. Proteinuria might reflect the hypertension, and VEGF inhibitor treatment is usually stopped when it reaches $3 \mathrm{~g}$ protein loss in $24 \mathrm{~h}$ (Burger et al., 2011). Although the treatment with bevacizumab (Avastin, which neutralizes specifically the VEGF-A isoforms) and paclitaxel plus carboplatin (both chemotherapeutics) in the treatment of patients with non-small-cell lung cancer had significant survival benefits, febrile neutropenia and pulmonary hemorrhage were associated with the addition of anti-VEGF (Sandler et al., 2006). Moreover, bevacizumab is avoided in patients with ovarian cancer with substantial pelvic disease or with previous bowel surgery for the risk of bowel perforation or fistula formation (Simpkins et al., 2007). Owing to the fact that TKIs inhibit a lot of off-target kinases, they are associated with malaise, fatigue, hypothyroidism, diarrhea, and cardiac failure (Schmidinger and Bellmunt, 2010).

\section{NEED FOR PRO-ANGIOGENIC THERAPY?}

Some cancer therapies are based on the association of an anti-angiogenic drug with an anti-tumor drug: the transitional restoration of normal blood vessels allows the drug to reach the tumor site (Jain, 2013). These effects, however, are limited spatially and temporally and are different in different types of cancer and therefore should clearly define the "normalization window" for so the anti-tumor drug can act with maximum efficiency (Figure 1A,b).

The approach to the treatment of the cancer with a proangiogenic therapy instead of anti-angiogenic, certainly opens up new horizons in therapeutic strategies and leads to a profound change from the clinical point of view. A pro-angiogenic drug can create, around the tumor mass, an extensive network of wellstructured blood vessels that facilitate the transport and thus the effectiveness of a cancer drug. 
Pericytes are very important in vessel stabilization and maturation, promoting vascular normalization. Data has shown that pericyte loss is a crucial event in early phases of tumor angiogenesis (Anfuso et al., 2014; Lupo et al., 2014; Salmeri et al., 2013). Their presence assure the prevention of metastasis (Xian et al., 2006) and the increment of oxygenation that enhances the sensitization to focal therapies and reduction of tumor growth (Cooke et al., 2012).

Pericyte recruitment is driven by PDGFR $\beta$ and its increased expression is a predictor of low survival in breast (Paulsson et al., 2009) and prostate cancers (Hagglof et al., 2010). It has been also demonstrated that PDGF overexpression is associated with increase of melanoma cells proliferation and increased pericyte abundance (Furuhashi et al., 2004). Unfortunately, treatment with imatinib (TKR inhibitor specific to PDGFR $\beta$ ) has not produced encouraging results in patients with metastatic nonsmall cell lung cancer (Tsao et al., 2011). Conversely, dual PDGFR $\beta$ /VEGFR inhibition is effective for treating multiple stages in tumorigenesis, particularly in solid tumors with high pericyte coverage (Bergers and Hanahan, 2008).

On the other hand, numerous studies have highlighted that the presence of pericytes stabilize tumor microvasculature and allows direct drug delivery to cancer cells (Lo Dico et al., 2015). An increased amount of pericyte on the tumor microvessels inhibits the angiogenesis, while the absence of pericyte coverage correlates with metastasis in colorectal cancer patients (Yonenaga et al., 2005). Particularly noteworthy is the role played by pericytes in response to anti-angiogenic therapy. It has been shown in a preclinical study that VEGFR2 blocking is able to determine the recruitment of pericytes, normalizing the tumor microcirculation and allowing the drug to penetrate inside the tumor (Greenberg et al., 2008).

\section{PREDICTIVE DETECTION}

In this scenario, identifying specific parameters, predictive of therapy success, could be necessary for the selection of a targeted anti-tumor drug. These parameters could be provided by imaging techniques (Figure 1B).

\section{Microvascular Density Analyses}

Measurements of vessel caliber by Magnetic Resonance Imaging (MRI) is a technique for in vivo monitoring of microvascular development during the treatment of cancer patients (Dennie et al., 1998). Some of MRI-based studies, have shown that treatment with anti-angiogenic drugs leads to an improvement in tumor microcirculation, which is less permeable and has an increased pericyte coverage (Goel et al., 2011). By using this technique, it is possible to obtain images of the structure of the tumor microvasculature (Vessel Architectural Imaging, VAI) whose evaluation provides an efficient parameter for monitoring disease progression and response to treatment in cancer patients. Emblem et al. (2013) conducted a retrospective analysis of 30 patients affected by glioblastoma and studied the structural heterogeneity of the tumor microcirculation by VAI, demonstrating that, during the anti-angiogenic therapy, tumor blood vessels of subjects who responded to treatment were similar to those of normal tissues (Sikov et al., 2015). Recent studies have shown a significant increase in the number of patients with breast cancer who are HER2-negative or triple negative and do not respond to conventional anti-angiogenic therapies (Earl et al., 2015), and that an improvement of vascular conditions causes an increase in tumor oxygenation and a better response to anti-angiogenic agents (Heist et al., 2015).

Tolaney et al. (2015) have demonstrated that high baseline microvascular density (MVD) in breast tumors is considered a positive response to vascular normalization index induced by bevacizumab. MVD is calculated by evaluating specific parameters including pericytes coverage and the number of $\alpha$-SMA. In the case of high MVD, the effect of anti-angiogenic drugs would be to remove some vessels and increase the functions of others, by inducing their normalization. In the case of low MVD, the anti-angiogenic drug reduces them further and prevents their normalization. This makes some tumors insensitive to anti-angiogenic therapy. Consequently, knowing the baseline MVD is a key factor in predicting the success of treatment with anti-angiogenic drugs (Jeong et al., 2015).

\section{Hypoxia Detection}

A characteristic of tumor microenvironment is low oxygen tension, caused by an imbalance in oxygen delivery and consumption. At low $\mathrm{pO}_{2}$ levels, cells become radioresistant and, as a vicious circle, the irradiation itself, which induces direct vessel damage, stimulates hypoxia with consequent recruitment of immunosuppressive myeloid cells, contributing to tumor resistance (Russell and Brown, 2013). Conversely, it has also been also demonstrated, in a xenograft tumor model, that VEGF is released at the onset of angiogenesis, independent of HIF (Hendriksen et al., 2009). These conflicting results are ascribable to the different origin of the tumors and to the different areas within the same tumor, characterized by chaotic and complex tumor vascular architecture that determines a better or worse oxygen distribution (Hida et al., 2016).

The lactate, produced by tumor glycolytic metabolism, predicts the response to irradiation of human carcinomas (Sattler et al., 2010), an increased risk of metastases (Brizel et al., 2001) and is able to induce angiogenesis (Hirschhaeuser et al., 2011). These findings indicate that the anaerobic metabolism of cancer cells is strongly related to the increased aggressiveness of a tumor and the possibility of measuring its amount is an important predictor.

HIF-1 activity can be silenced through inhibition of epidermal growth factor receptor (EGFR) or topoisomerase-1 or by anthracyclines (Semenza, 2010). Moreover, HIF-1 activity can be inhibited by new drugs which reduces HIF-1 mRNA amounts (Koh et al., 2008) or which provokes HIF-1 degradation (Kim et al., 2006). The treatment with these drugs during radiotherapy amplifies the irradiation effects prompting tumor vasculature destruction and reduction in growth (Harada et al., 2009). Unfortunately, these exciting results did not apply to all types of tumor because several cancers show little or no hypoxia and do not express HIF activation (Moeller and Dewhirst, 2006; Meijer et al., 2012). 
Tumor hypoxia represents an important aspect of the tumor microenvironment. Clinical studies using needle-sensors (Eppendorf) ${ }^{\circledR}$ have demonstrated that hypoxia varied on a tumor-to-tumor basis and represents a universal therapy resistance mechanism (Koch and Evans, 2015). For this reason, several methods have been developed to assess tumor hypoxia and to predict treatment outcome by evaluating the oxygenation status during therapy.

Several studies have been conducted to determine the presence of HIF inside tumor cells. Recent advances in imaging of hypoxia by positron emission tomography (PET) demonstrated that it is possible to select patients for specific therapies, improving the anti-hypoxia-direct radiotherapy (Baumann et al., 2016). Activation of HIF transcription factor can be also evaluated by using genetically encoded fluorescent sensors with different switching and their combination allows the distinction of hypoxic and re-oxygenated cells in glioma cell lines, focusing on regions devoid of blood vessels (Erapaneedi et al., 2016). A potential tracer, used as a biomarker in the context of anti-angiogenic therapy, is $\left[{ }^{18} \mathrm{~F}\right]$-FMISO: a low $\left[{ }^{18} \mathrm{~F}\right]$-FMISO-PET signal is correlated to decreased hypoxia and it is a predictor of vascular normalization (Hernandez-Agudo et al., 2016).

The dynamic contrast enhanced magnetic resonance imaging (DCE-MRI) technique has been used to evaluate the effect of bortezomib, by using multiple endogenous and exogenous markers to evaluate hypoxia (Sun et al., 2014). By DCE-MRI it has been demonstrated that tumor blood flow is significantly reduced after bortezomib administration and the results of this study are very important to monitoring the effects of treatment with an anti-tumoral drug.

It has been recently reported that a hypoxia visualization bio-imaging probe, protein transduction domain [PTD]-oxygen dependent degradation domain [ODD]-HaloTag $(\mathrm{POH})$, was able to detect HIF-1 active (Takata et al., 2015).

HIF activity has also been monitored in a preclinical glioma model. After treatment with different drugs, imaging biomarkers

\section{REFERENCES}

Adya, R., Tan, B. K., Punn, A., Chen, J., and Randeva, H. S. (2008). Visfatin induces human endothelial VEGF and MMP-2/9 production via MAPK and PI3 K/Akt signalling pathways: novel insights into visfatin-induced angiogenesis. Cardiovasc. Res. 78, 356-365. doi: 10.1093/cvr/cvm111

Allegra, C. J., Yothers, G., O’Connell, M. J., Sharif, S., Petrelli, N. J., Lopa, S. H., et al. (2013). Bevacizumab in stage II-III colon can- cer: 5-year update of the National Surgical Adjuvant Breast and Bowel Project C-08 trial. J. Clin. Oncol. 31, 359-364. doi: 10.1200/JCO.2012.44.4711

Anfuso, C. D., Motta, C., Giurdanella, G., Arena, V., Alberghina, M., and Lupo, G. (2014). Endothelial PKC $\alpha$-MAPK/ERK-phospholipase A2 pathway activation as a response of glioma in a triple culture model. A new role for pericytes? Biochimie 99, 77-87. doi: 10.1016/j.biochi.2013. 11.013

Baumann, R., Depping, R., Delaperriere, M., and Dunst, J. (2016). Targeting hypoxia to overcome radiation resistance in head \& neck cancers: real challenge or clinical fairytale? Expert Rev. Anticancer Ther. 16, 751-758. doi: 10.1080/ 14737140.2016.1192467

Bennouna, J., Sastre, J., Arnold, D., Osterlund, P., Greil, R., Van Cutsem, E., et al. (2013). Continuation of bevacizumab after first progression in metastatic colorectal cancer (ML18147): a randomised phase 3 trial. Lancet Oncol. 14, 29-37. doi: 10.1016/S1470-2045(12)70477-1 through luciferase expression have been used to document the tumor response (Lo Dico et al., 2015).

\section{CONCLUSION}

The authors believe that these studies show alternative therapeutic pathways, capable of inducing the differentiation and maturation of tumor blood vessels. In our opinion, the recruitment of pericytes must be taken into account for new strategies in the fight against those tumors, which are especially drug-resistant to traditional therapies.

These studies on new target tracers represent a useful tool for theranostic procedures.

\section{AUTHOR CONTRIBUTIONS}

CA and GL designed the study. NC, MO, and MC collected the data reported in Table 1. CA and GL wrote the manuscript and drew the Figure 1. FN, RA, VB, CM, and MS added the helpful discussions. CA, GL, and FN edited the manuscript, figure and table.

\section{FUNDING}

This article was supported by the National Grant PON01_02464.

\section{ACKNOWLEDGMENTS}

We acknowledge the National Grant PON01_02464 for the financial support in this Research Topic. We greatly thank Mr. Giovanni Pachera for the excellent support in the creation of images and Mrs. Valerie Bailey for the English proofreading.

Bergers, G., and Hanahan, D. (2008). Modes of resistance to anti- angiogenic therapy. Nat. Rev. Cancer 8, 592-603. doi: 10.1038/nrc2442

Brizel, D. M., Schroeder, T., Scher, R. L., Walenta, S., Clough, R. W., Dewhirst, M. W., et al. (2001). Elevated tumor lactate concentrations predict for an increased risk of metastases in head-and-neck cancer. Int. J. Radiat. Oncol. Biol. Phys. 51, 349-353. doi: 10.1016/S0360-3016(01)01630-3

Brose, M. S., Nutting, C. M., Jarzab, B., Elisei, R., Sienna, S., Bastholt, L., et al. (2014). Sorafenib in radioactive iodine-refractory, locally advanced or metastatic differentiated thyroid cancer: a randomised, double-blind, phase 3 trial. Lancet 384, 319-328. doi: 10.1016/S0140-6736(14)60421-9

Bruix, J., Takayama, T., Mazzaferro, V., Chau, G. Y., Yang, J., Kudo, M., et al. (2015). Adjuvant sorafenib for hepatocellular carcinoma after resection or ablation (STORM): a phase 3, randomised, double-blind, placebo-controlled trial. Lancet Oncol. 16, 1344-1354. doi: 10.1016/S1470-2045(15)00198-9

Burger, R. A., Brady, M. F., Bookman, M. A., Fleming, G. F., Monk, B. J., Huang, H., et al. (2011). Incorporation of bevacizumab in the primary treatment of ovarian cancer. N. Engl. J. Med. 365, 2473-2483. doi: 10.1056/NEJMoa1104390

Cainap, C., Qin, S., Huang, W. T., Chung, I. J., Pam, H., Cheng, Y., et al. (2015). Linifanib versus Sorafenib in patients with advanced hepatocellular carcinoma: results of a randomized phase III trial. J. Clin. Oncol. 33, 172-179. doi: 10.1200/ JCO.2013.54.3298

Chen, H. X., and Cleck, J. N. (2009). Adverse effects of anticancer agents that target the VEGF pathway. Nat. Rev. Clin. Oncol. 6, 465-477. doi: 10.1038/nrclinonc 
Chung, A. S., Kowanetz, M., Wu, X., Zhuang, G., Ngu, H., Finkle, D., et al. (2012). Differential drug class-specific metastatic effects following treatment with a panel of angiogenesis inhibitors. J. Pathol. 227, 404-416. doi: 10.1002/path.4052

Chung, A. S., Wu, X., Zhuang, G., Ngu, H., Kasman, I., Zhang, J., et al. (2013). An interleukin-17-mediated paracrine network promotes tumor resistance to anti-angiogenic therapy. Nat. Med. 19, 1114-1123. doi: 10.1038/nm.3291

Cooke, V. G., Lebleu, V. S., Keskin, D., Khan, Z., O’Connell, J. T., Teng, Y., et al. (2012). Pericyte depletion results in hypoxia- associated epithelial-tomesenchymal transition and metastasis mediated by met signaling pathway. Cancer Cell 21, 66-68. doi: 10.1016/j.ccr.2011.11.024

Crawford, Y., Kasman, I., Yu, L., Zhong, C., Wu, X., Modrusan, Z., et al. (2009). PDGF-C mediates the angiogenic and tumorigenic properties of fibroblasts associated with tumors refractory to anti-VEGF treatment. Cancer Cell 15, 21-34. doi: 10.1016/jccr.2008.12.004

de Gramont, A., Van Cutse, E., Schmoll, H. J., Tabernero, J., Clarke, S., Moore, M. J., et al. (2012). Bevacizumab plus oxaliplatin-based chemotherapy as adjuvant treatment for colon cancer (AVANT): a phase 3 randomised controlled trial. Lancet Oncol. 13, 1225-1233. doi: 10.1016/S1470-2045(12)70509-0

Dennie, J., Mandeville, J. B., Boxerman, J. L., Packard, S. D., Rosen, B. R., and Weisskoff, R. M. (1998). NMR imaging of changes in vascular morphology due to tumour angiogenesis. Magn. Reson. Med. 1998, 793-799. doi: 10.1002/mrm. 1910400602

Earl, H. M., Hiller, L., Dunn, J. A., Blenkinsop, C., Grybowicz, L., Vallier, A. L., et al. (2015). Efficacy of neoadjuvant bevacizumab added to docetaxel followed by fluorouracil, epirubicin, and cyclophosphamide, for women with HER2negative early breast cancer (ARTemis): an open-label, randomised, phase 3 trial. Lancet Oncol. 16, 656-666. doi: 10.1016/S1470-2045(15)70137-3

Ebos, J. M., Lee, C. R., Cruz-Munoz, W., Bjarnason, G. A., Christensen, J. G., and Kerbel, R. S. (2009). Accelerated metastasis after short-term treatment with a potent inhibitor of tumor angiogenesis. Cancer Cell 15, 232-239. doi: 10.1016/j.ccr.2009.01.021

Emblem, K. E., Mouridsen, K., Bjornerud, A., Farrar, C. T., Jennings, D., Borra, R. J. H., et al. (2013). Vessel architectural imaging identifies cancer patient responders to anti-angiogenic therapy. Nat. Med. 19, 1178-1183. doi: 10.1038/ nm.3289

Erapaneedi, R., Belousov, V. V., Schäfers, M., and Kiefer, F. (2016). A novel family of fluorescent hypoxia sensors reveal strong heterogeneity in tumor hypoxia at the cellular level. EMBO J. 35, 102-113. doi: 10.15252/embj.201592775

Fakhrejahani, E., and Toi, M. (2014). Antiangiogenesis therapy for breast cancer: an update and perspectives from clinical trials. Jpn. J. Clin. Oncol. 44, 197-207. doi: $10.1093 /$ jjco/hyt201

Folberg, R., and Maniotis, A. J. (2004). Vasculogenic mimicry. APMIS 112, 508-525. doi: 10.1111/j.1600-0463.2004.apm11207-0810.x

Fuchs, C. S., Tomasek, J., Yong, C. J., Dumitru, F., Passalacqua, R., Goswami, C., et al. (2014). Ramucirumab monotherapy for previously treated advanced gastric or gastro-oesophageal junction adenocarcinoma (REGARD): an international, randomised, multicentre, placebo-controlled, phase 3 trial. Lancet 383, 31-39. doi: 10.1016/S0140-6736(13)61719-5

Furuhashi, M., Sjoblom, T., Abramsson, A., Ellingsen, J., Micke, P., Li, H., et al. (2004). Platelet-derived growth factor production by B16 melanoma cells leads to increased pericyte abundance in tumors and an associated increase in tumor growth rate. Cancer Res. 64, 2725-2733. doi: 10.1158/0008-5472.CAN-03-1489

Garon, E. B., Ciuleanu, T. E., Arrieta, O., Prabhash, K., Syrigos, K. N., Goksel, T., et al. (2014). Ramucirumab plus docetaxel versus placebo plus docetaxel for second-line treatment of stage IV non-small-cell lung cancer after disease progression on platinum-based therapy (REVEL): a multicentre, double-blind, randomised phase 3 trial. Lancet 384, 665-673. doi: 10.1016/S0140-6736(14) 60845

Gilbert, M. R., Dignam, J. J., Armstrong, T. S., Wefel, J. S., Blumenthal, D. T., Vogelbaum, M. A., et al. (2014). A randomized trial of bevacizumab for newly diagnosed glioblastoma. N. Engl. J. Med. 370, 699-708. doi: 10.1056/ NEJMoa1308573

Goel, S., Duda, D. G., Xu, L., Munn, L. L., Boucher, Y., Fukumura, D., et al. (2011). Normalization of the vasculature for treatment of cancer and other diseases. Physiol. Rev. 91, 1071-1121. doi: 10.1152/physrev.00038.2010

Greenberg, J. I., Shields, D. J., Barillas, S. G., Acevedo, L. M., Murphy, E., Huang, J., et al. (2008). A role for VEGF as a negative regulator of pericyte function and vessel maturation. Nature 456, 809-813. doi: 10.1038/nature07424
Grothey, A., Van Cutsem, E., Sobrero, A., Siena, S., Falcone, A., Ychou, M., et al. (2013). Regorafenib monotheraphy for previously treated metastatic colorectal cancer (CORRECT): an international, multicenter, randomized, placebo-controlled, phase 3 trial. Lancet 381, 303-312. doi: 10.1016/S01406736(12)61900-X

Gu, L., Zhu, N., Zhang, H., Durden, D. L., Feng, Y., and Zhou, M. (2009). Regulation of XIAP translation and induction by MDM2 following irradiation. Cancer Cell 15, 363-375. doi: 10.1016/j.ccr.2009.03.002

Hagglof, C., Hammarsten, P., Josefsson, A., Stattin, P., Paulsson, J., Bergh, A., et al. (2010). Stromal PDGFRbeta expression in prostate tumors and nonmalignant prostate tissue predicts prostate cancer survival. PLoS ONE 5:e10747. doi: 10.1371/journal.pone.0010747

Harada, H., Itasaka, S., Zhu, Y., Zeng, L., Xie, X., Morinibu, A., et al. (2009). Treatment regimen determines whether an HIF-1 inhibitor enhances or inhibits the effect of radiation therapy. Br. J. Cancer 100, 747-757. doi: 10.1038/sj.bjc. 6604939

Heist, R. S., Dusa, D. G., Sahani, D. V., Ancukiewicz, M., Fidias, P., Sequist, L. V., et al. (2015). Improved tumour vascularization after anti-VEGF therapy with carboplatin and nab-paclitaxel associates with survival in lung cancer. Proc. Natl. Acad. Sci. U.S.A. 112, 1547-1552. doi: 10.1073/pnas.1424024112

Hendriksen, E. M., Span, P. N., Schuuring, J., Peters, J. P., Sweep, F. C., van der Kogel, A. J., et al. (2009). Angiogenesis, hypoxia and VEGF expression during tumour growth in a human xenograft tumourmodel. Microvasc. Res. 77, 96-103. doi: 10.1016/j.mvr.2008.11.002

Hernandez-Agudo, E., Mondejar, T., Soto-Montenegro, M. L., Megl as, D., Mouron, S., Sanchez, J., et al. (2016). Monitoring vascular normalization induced by antiangiogenic treatment with 18F-fluoromisonidazole-PET. Mol. Oncol. 10, 704-718. doi: 10.1016/j.molonc.2015.12.011

Hida, K., Maishi, N., Torii, C., and Hida, Y. (2016). Tumour angiogenesischaracteristics of tumor endothelial cells. Int. J. Clin. Oncol. 21, 206-212. doi: 10.1007/s10147-016-0957-1

Hirschhaeuser, F., Sattler, U. G., and Mueller-Klieser, W. (2011). Lactate: a metabolic key player in cancer. Cancer Res. 71, 6921-6925. doi: 10.1158/00085472

Huang, Y., Goel, S., Duda, D. G., Fukumura, D., and Jain, R. K. (2013). Vascular normalization as an emerging strategy to enhance cancer immunotherapy. Cancer Res. 73, 2943-2948. doi: 10.1158/0008-5472

Hutson, T. E., Escudier, B., Esteban, E., Bjarnason, G. A., Lim, H. Y., Pittman, K. B., et al. (2014). Randomized phase III trial of temsirolimus versus sorafenib as second-line therapy after sunitinib in patients with metastatic renal cell carcinoma. J. Clin. Oncol. 32, 760-767. doi: 10.1200/JCO.2013. 50.3961

Jain, R. K. (2013). Normalizing tumor microenvironment to treat cancer: bench to bedside to biomarkers. J. Clin. Oncol. 31, 2205-2218. doi: 10.1200/JCO.2012.46. 3653

Jeong, H. S., Jones, D., Liao, S., Wattson, D. A., Cui, C. H., Duda, D. G., et al. (2015). Investigation of the lack of angiogenesis in the formation of lymph node metastases. J. Natl. Cancer Inst. 107:djv155. doi: 10.1093/jnci/djv155

Keunen, O., Johansson, M., Oudin, A., Sanzey, M., Rahim, S. A., Fack, F., et al. (2011). Anti-VEGF treatment reduces blood supply and increases tumor cell invasion in glioblastoma. Proc. Natl. Acad. Sci. U.S.A. 108, 3749-3754. doi: 10.1073/pnas. 1014480108

Kilarski, W. W., Samolov, B., Petersson, L., Kvanta, A., and Gerwins, P. (2009). Biomechanical regulation of blood vessel growth during tissue vascularization. Nat. Med. 15, 657-664. doi: 10.1038/nm.1985

Kim, H. L., Yeo, E. J., Chun, Y. S., and Park, J. W. (2006). A domain responsible for HIF- 1alpha degradation by YC-1, a novel anticancer agent. Int. J. Oncol. 29, 255-260.

Kindler, H. L., Niedzwiecki, D., Hollis, D., Sutherland, S., Schrag, D., Hurwitz, H., et al. (2010). Gemcitabine plus bevacizumab compared with gemcitabine plus placebo in patients with advanced pancreatic cancer: phase III trial of the Cancer and Leukemia Group B (CALGB 80303). J. Clin. Oncol. 28, 3617-3622. doi: $10.1200 /$ JCO.2010.28.1386

Koch, C. J., and Evans, S. M. (2015). Optimizing hypoxia detection and treatment strategies. Semin. Nucl. Med. 45, 163-176. doi: 10.1053/j.semnuclmed.2014.10. 004

Koh, M. Y., Spivak-Kroizman, T., Venturini, S., Welsh, S., Williams, R. R., Kirkpatrick, D. L., et al. (2008). Molecular mechanisms for the activity of PX- 
478, an antitumor inhibtor of the hypoxia-inducible factor-1alpha. Mol. Cancer Ther. 7, 90-100. doi: 10.1158/1535-7163.MCT-07-0463

Liang, W., Wu, X., Hong, S., Zhang, Y., Kang, S., and Fang, W. (2014). Multitargeted antiangiogenic tyrosine kinase inhibitors in advanced non-small cell lung cancer: meta-analyses of 20 randomized controlled trials and subgroup analyses. PLoS ONE 9:e109757. doi: 10.1371/journal.pone.0109757

Lo Dico, A., Martelli, C., Valtorta, S., Raccagni, I., Diceglie, C., and Belloli, S. (2015). Identification of imaging biomarkers for the assessment of tumour response to different treatments in a preclinical glioma model. Eur. J. Nucl. Med. Mol. Imaging 42, 1093-1105. doi: 10.1007/s00259-015-3040-7

Lu, K. V., Chang, J. P., Parachoniak, C. A., Pandika, M. M., Aghi, M. K., Meyronet, D., et al. (2012). VEGF inhibits tumor cell invasion and mesenchymal transition through a MET/VEGFR2 complex. Cancer Cell 22, 21-35. doi: 10.1016/j.ccr.2012.05.037

Lupo, G., Motta, C., Salmeri, M., Spina-Purrello, V., Alberghina, M., and Anfuso, C. D. (2014). An in vitro retinoblastoma human triple culture model of angiogenesis: a modulatory effect of TGF- $\beta$. Cancer Lett. 354, 181-188. doi: 10.1016/j.canlet.2014.08.004

Maes, H., Olmeda, D., Soengas, M. S., and Agostinis, P. (2016). Vesicular trafficking mechanisms in endothelial cells as modulators of the tumor vasculature and targets of antiangiogenic therapies. FEBS J. 283, 25-38. doi: 10.1111/febs. 13545

Matsuda, K., Ohga, N., Hida, Y., Muraki, C., Tsuchiya, K., Kurosu, T., et al. (2010). Isolated tumor endothelial cells maintain specific character during long-term culture. Biochem. Biophys. Res. Commun. 394, 947-954. doi: 10.1016/j.bbrc. 2010.03.089

McIntyre, A., Patiar, S., Wigfield, S., Li, J., Ledaki, I., Turley, H., et al. (2012). Carbonic anhydrase IX promotes tumor growth and necrosis in vivo and inhibition enhances anti-VEGF therapy. Clin. Cancer Res. 18, 3100-3111. doi: 10.1158/1078-0432.CCR-11-1877

McMillin, D. W., Negri, J. M., and Mitsiades, C. S. (2013). The role of tumourstromal interactions in modifying drug response: challenges and opportunities. Nat. Rev. Drug Discov. 12, 217-228. doi: 10.1038/nrd3870

Meijer, T. W., Kaanders, J. H., Span, P. N., and Bussink, J. (2012). Targeting hypoxia, HIF-1, and tumor glucose metabolism to improve radiotherapy efficacy. Clin. Cancer Res. 18, 5585-5594. doi: 10.1158/1078-0432.CCR-12-0858

Michaelson, M. D., Oudard, S., Ou, Y. C., Sengeløv, L., Saad, F., Houede, N., et al. (2014). Randomized, placebo-controlled, phase III trial of sunitinib plus prednisone versus prednisone alone in progressive, metastatic, castrationresistant prostate cancer. J. Clin. Oncol. 32, 76-82. doi: 10.1200/JCO.2012.48. 5268

Miller, K. D., Sweeney, C. J., and Sledge, G. W. Jr. (2005). Can tumor angiogenesis be inhibited without resistance? EXS 94, 95-112. doi: 10.1007/3-7643-7311-3_7

Moeller, B. J., and Dewhirst, M. W. (2006). HIF-1 and tumour radiosensitivity. Br. J. Cancer 95, 1-5. doi: 10.1038/sj.bjc.6603201

Nagy, J. A., and Dvorak, H. F. (2012). Heterogeneity of the tumor vasculature: the need for new tumour blood vessel type-specific targets. Clin. Exp. Metastasis 29, 657-662. doi: 10.1007/s10585-012-9500-6

Nanda, A., and Croix, B. S. (2004). Tumor endothelial markers: new targets for cancer therapy. Curr. Opin. Oncol. 16, 44-49. doi: 10.1097/00001622200401000-00009

Nico, B., Crivellato, E., Guidolin, D., Annese, T., Longo, V., Finato, N., et al. (2010). Intussusceptive microvascular growth in human glioma. Clin. Exp. Med. 10, 93-98. doi: 10.1007/s10238-009-0076-7

Ohga, N., Ishikawa, S., Maishi, N., Akiyama, K., Hida, Y., Kawamoto, T., et al. (2012). Heterogeneity of tumor endothelial cells: comparison between tumor endothelial cells isolated from high- and low-metastatic tumors. Am. J. Pathol. 180, 1294-1307. doi: 10.1016/j.ajpath.2011.11.035

Paulsson, J., Sjöblom, T., Micke, P., Pontén, F., Landberg, G., Heldin, C. H., et al. (2009). Prognostic significance of stromal platelet- derived growth factor betareceptor expression in human breast cancer. Am. J. Pathol. 175, 334-341. doi: 10.2353/ajpath.2009.081030

Powles, T., Kayani, I., Sharpe, K., Lim, L., Peters, J., Stewart, G. D., et al. (2013). A prospective evaluation of VEGF-targeted treatment cessation in metastatic clear cell renal cancer. Ann. Oncol. 24, 2098-2103. doi: 10.1093/annonc/ mdt 130

Pujade-Lauraine, E., Hilpert, F., Weber, B., Reuss, A., Poveda, A., Kristensen, G., et al. (2014). Bevacizumab combined with chemotherapy for platinum-resistant recurrent ovarian cancer: the AURELIA open-label randomized phase III trial. J. Clin. Oncol. 32, 1302-1308. doi: 10.1200/JCO.2013.51.4489

Rak, J., Yu, J. L., Kerbel, R. S., and Coomber, B. L. (2002). What do oncogenic mutations have to do with angiogenesis/vascular dependence of tumors? Cancer Res. 62, 1931-1934.

Rini, B. I., Bellmunt, J., Clancy, J., Wang, K., Niethammer, A. G., Hariharan, S., et al. (2014). Randomized phase III trial of temsirolimus and bevacizumab versus interferon alfa and bevacizumab in metastatic renal cell carcinoma: INTORACT trial. J. Clin. Oncol. 32, 752-759. doi: 10.1200/JCO.2013.50.5305

Russell, J. S., and Brown, J. M. (2013). The irradiated tumor microenvironment: role of tumor-associated macrophages in vascular recovery. Front. Physiol. 17:157. doi: 10.3389/fphys.2013.00157

Salmeri, M., Motta, C., Anfuso, C. D., Amodeo, A., Scalia, M., Toscano, M. A., et al. (2013). VEGF receptor-1 involvement in the pericyte loss induced by E. coli in an in vitro model of blood brain barrier. Cell. Microbiol. 8, 1367-1384. doi: $10.1111 / \mathrm{cmi} .12121$

Saltz, L. B., Lenz, H.-J., Kindler, H. L., Hochster, H. S., Wadler, S., Hoff, P. M., et al. (2007). Randomized phase II trial of cetuximab, bevacizumab, and irinotecan compared with cetuximab and bevacizumab alone in irinotecan-refractory colorectal cancer: the BOND-2 study. J. Clin. Oncol. 25, 4557-4561. doi: 10. 1200/JCO.2007.12.0949

Sandler, A., Gray, R., Perry, M. C., Brahmer, J., Schiller, J. H., Dowlati, A., et al. (2006). Paclitaxel-carboplatin alone or with bevacizumab for non-small-cell lung cancer. N. Engl. J. Med. 14, 2542-2550. doi: 10.1056/NEJMoa061884

Sattler, U. G., Meyer, S. S., Quennet, V., Hoerner, C., Knoerzer, H., Fabian, C., et al. (2010). Glycolytic metabolism and tumour response to fractionated irradiation. Radiother. Oncol. 94, 102-109. doi: 10.1016/j.radonc.2009.11.007

Schmidinger, M., and Bellmunt, J. (2010). Plethora of agents, plethora of targets, plethora of side effects in metastatic renal cell carcinoma. Cancer Treat. Rev. 36, 416-424. doi: 10.1016/j.ctrv.2010.01.003

Seaman, S., Stevens, J., Yang, M. Y., Logsdon, D., Graff-Cherry, C., and St Croix, B. (2007). Genes that distinguish physiological and pathological angiogenesis. Cancer Cell 11, 539-554. doi: 10.1016/j.ccr.2007.04.017

Semenza, G. L. (2010). Defining the role of hypoxia-inducible factor 1 in cancer biology and therapeutics. Oncogene 29, 625-634. doi: 10.1038/onc.2009.441

Shaked, Y., Ciarrocchi, A., Franco, M., Lee, C. R., Man, S., Cheung, A. M., et al. (2006). Therapy-induced acute recruitment of circulating endothelial progenitor cells to tumors. Science 22, 1785-1787. doi: 10.1126/science.1127592

Sharpe, K., Stewart, G. D., Mackay, A., Van Neste, C., Rofe, C., Berney, D., et al. (2013). The effect of VEGF targeted therapy on biomarker expression in sequential tissue from patients with metastatic clear cell renal cancer. Clin. Cancer Res. 19, 6924-6934. doi: 10.1158/1078-0432.CCR-13-1631

Sherrill, K. W., Byrd, M. P., Van Eden, M. E., and Lloyd, R. E. (2004). BCL-2 translation is mediated via internal ribosome entry during cell stress. J. Biol. Chem. 279, 29066-29074. doi: 10.1074/jbc.M402727200

Shojaei, F., Wu, X., Zhong, C., Yu, L., Liang, X. H., Blanchard, D., et al. (2007). Bv8 regulates myeloid-cell-dependent tumour angiogenesis. Nature 450, 825-831. doi: 10.1038/nature06348

Sikov, W. M., Berry, D. A., Perou, C. M., Singh, B., Cirrincione, C. T., Tolaney, A. M., et al. (2015). Impact of the addition of carboplatin and/or bevacizumab to neoadjuvant once-per-week paclitaxel followed by dose-dense doxorubicin and cyclophosphamide on pathologic complete response rates in stage II to III triple-negative breast cancer: CALGB 40603 (Alliance). J. Clin. Oncol. 33, 13-21. doi: 10.1200/JCO.2014.57.0572

Simpkins, F., Belinson, J. L., and Rose, P. G. (2007). Avoiding bevacizumab related gastrointestinal toxicity for recurrent ovarian cancer by careful patient screening. Gynecol. Oncol. 107, 118-123. doi: 10.1016/j.ygyno.2007.06.004

Sitohy, B., Nagy, J. A., and Dvorak, H. F. (2012). Anti-VEGF/VEGFR therapy for cancer: reassessing the target. Cancer Res. 72, 1909-1914. doi: 10.1158/00085472.CAN-11-3406

Somers, J., Wilson, L. A., Kilday, J. P., Horvilleur, E., Cannell, I. G., Pöyry, T. A., et al. (2015). A common polymorphism in the 5' UTR of ERCC5 creates an upstream ORF that confers resistance to platinum-based chemotherapy. Genes Dev. 29, 1891-1896. doi: 10.1101/gad.261867.115

Straume, O., Chappuis, P. O., Salvesen, H. B., Halvorsen, O. J., Haukaas, S. A., Goffin, J., et al. (2002). Prognostic importance of glomeruloid microvascular proliferation indicates an aggressive angiogenic phenotype in human cancers. Cancer Res. 62, 6808-6811. 
Sun, M., Larcher, A., and Karakiewicz, P. I. (2014). Optimal first-line and secondline treatments for metastatic renal cell carcinoma: current evidence. Int. J. Nephrol. Renovasc. Dis. 7, 401-407. doi: 10.2147/IJNRD.S48496

Takata, S., Masuda, T., Nakamura, S., Kuchimaru, T., Tsuruma, K., Shimazawa, M., et al. (2015). The effect of triamcinolone acetonide on laser-induced choroidal neovascularization in mice using a hypoxia visualization bio-imaging probe. Sci. Rep. 30:9898. doi: 10.1038/srep09898

Taylor, S. M., Nevis, K. R., Park, H. L., Rogers, G. C., Rogers, S. L., Cook, J. G., et al. (2010). Angiogenic factor signaling regulates centrosome duplication in endothelial cells of developing blood vessels. Blood 116, 3108-3117. doi: 10 . 1182/blood-2010-01-266197

Teng, L. S., Jin, K. T., He, K. F., Wang, H. H., Cao, J., and Yu, D. C. (2010). Advances in combination of antiangiogenic agents targeting VEGF-binding and conventional chemotherapy and radiation for cancer treatment. J. Chin. Med. Assoc. 73, 281-288. doi: 10.1016/S1726-4901(10)70062-9

Tewari, K. S., Sill, M. W., Long, H. J. III, Penson, R. T., Huang, H., Ramondetta, L. M., et al. (2014). Improved survival with bevacizumab in advanced cervical cancer. N. Engl. J. Med. 370, 734-743. doi: 10.1056/NEJMoa1309748

Tolaney, S. M., Boucher, Y., Duda, D. G., Martin, J. D., Seano, G., Ancukiewicz, M., et al. (2015). Role of vascular density and normalization in response to neoadjuvant bevacizumab and chemotherapy in breast cancer patients. Proc. Natl. Acad. Sci. U.S.A. 112, 14325-14330. doi: 10.1073/pnas

Tsao, A. S., Liu, S., Fujimoto, J., Wistuba, I. I., Lee, J. J., Marom, E. M., et al. (2011). Phase II trials of imatinib mesylate and docetaxel in patients with metastatic non-small cell lung cancer and head and neck squamous cell carcinoma. J. Thorac. Oncol. 6, 2104-2111. doi: 10.1097/JTO.0b013e31822e7256

Uniacke, J., Holterman, C. E., Lachance, G., Franovic, A., Jacob, M. D., Fabian, M. R., et al. (2012). An oxygen-regulated switch in the protein synthesis machinery. Nature 486, 126-129. doi: 10.1038/nature11055

Wang, R., Chadalavada, K., Wilshire, J., Kowalik, U., Hovinga, K. E., Geber, A., et al. (2010). Glioblastoma stem-like cells give rise to tumor endothelium. Nature 468, 829-833. doi: 10.1038/nature09624

Wilke, H., Muro, K., Van Cutsem, E., Oh, S. C., Bodoky, G., Shimada, Y., et al. (2014). Ramucirumab plus paclitaxel versus placebo plus paclitaxel in patients with previously treated advanced gastric or gastro-oesophageal junction adenocarcinoma (RAINBOW): a double-blind, randomised phase 3 trial. Lancet Oncol. 15, 1224-1235. doi: 10.1016/S1470-2045(14) 70420-6

Winkler, F., Kozin, S. V., Tong, R. T., Chae, S. S., Booth, M. F., Garkavtsev, I., et al. (2004). Kinetics of vascular normalization by VEGFR2 blockade governs brain tumor response to radiation: role of oxygenation, angiopoietin-1, and matrix metalloproteinases. Cancer Cell 6, 553-563. doi: 10.1016/j.ccr.2004.10.011

Xian, X., Håkansson, J., Ståhlberg, A., Lindblom, P., Betsholtz, C., Gerhardt, H., et al. (2006). Pericytes limit tumor cell metastasis. J. Clin. Invest. 116, 642-651. doi: 10.1172/JCI25705

Xu, J., Wang, J., Xu, B., Ge, H., Zhou, X., and Fang, J. Y. (2013). Colorectal cancer cells refractory to anti-VEGF treatment are vulnerable to glycolytic blockade due to persistent impairment of mitochondria. Mol. Cancer Ther. 12, 717-724. doi: 10.1158/1535-7163.MCT-12-1016-T

Yonenaga, Y., Mori, A., Onodera, H., Yasuda, S., Oe, H., Fujimoto, A., et al. (2005). Absence of smooth muscle actin-positive pericyte coverage of tumor vessels correlates with hematogenous metastasis and prognosis of colorectal cancer patients. Oncology 69, 159-166. doi: 10.1159/000087840

Yu, J. L., Rak, J. W., Coomber, B. L., Hicklin, D. J., and Kerbel, R. S. (2002). Effect of p53 status on tumor response to antiangiogenic therapy. Science 22, 1526-1528. doi: $10.1126 /$ science. 1068327

Conflict of Interest Statement: The authors declare that the research was conducted in the absence of any commercial or financial relationships that could be construed as a potential conflict of interest.

Copyright (c) 2017 Lupo, Caporarello, Olivieri, Cristaldi, Motta, Bramanti, Avola, Salmeri, Nicoletti and Anfuso. This is an open-access article distributed under the terms of the Creative Commons Attribution License (CC BY). The use, distribution or reproduction in other forums is permitted, provided the original author(s) or licensor are credited and that the original publication in this journal is cited, in accordance with accepted academic practice. No use, distribution or reproduction is permitted which does not comply with these terms. 